\title{
Mário de Andrade e a escrita epistolar
}

\author{
Felipe de Andrade Constancio ${ }^{\mathrm{i}}$
}

\section{RESUMO}

A figura de Mário de Andrade ainda é indecifrável nas letras do modernismo brasileiro, por conta de suas facetas estéticas e culturais. Ainda há muito para se investigar sobre esse ícone da nossa cultura. Partindo desse viés investigativo, este trabalho trilha o percurso de uma possível (re)leitura da correspondência do autor de Macunaíma. Valendo-nos de três cartas publicadas no livro A lição do amigo (1982), busca-se investigar a intervenção estética operada pelo modernista no texto de Carlos Drummond de Andrade e no seu próprio fazer enquanto literato. Para tanto, recorre-se ao aparato teórico das escritas da intimidade, como uma corrente de estudos pós-modernistas em que se nota incidentemente a temática das escritas de si e das escritas do outro. Nossa hipótese de trabalho apoia-se neste fator: a intervenção de Mário de Andrade no texto e na formação intelectual de Drummond sinaliza-nos que ambos são figuras primordiais da escrita epistolar no século XX.

Palavras-chave: Cartas; Confissão; Escritas da intimidade.

\begin{abstract}
The figure of Mário de Andrade is still indecipherable in the letters of Brazilian modernism, due to its aesthetic and cultural facets. There is still a lot to investigate about this icon in our culture. Departing from this investigative line, this paper traces the path of a possible (re)reading of the correspondence of the author of Macunaima. Making use of three letters published in the book The lesson of the friend (1982), I aim to investigate the aesthetic intervention operated by the modernist artist in Carlos Drummond de Andrade's text and in his own work as a literary man. For this purpose, I employ the theoretical apparatus of the writings of intimacy, as a chain of postmodernist studies in which the theme of the writings of oneself and the writings of the other is incidentally noted. My working hypothesis is based on this factor: the intervention of Mário de Andrade in Drummond's text and intellectual formation signals that both are primordial figures of epistolary writing in the 20th century.
\end{abstract}

Keywords: Letters; Confession; Intimacy writing.

\footnotetext{
${ }^{i}$ Doutorando em Letras pela Universidade do Estado do Rio de Janeiro (início em 2019). Professor de Língua Portuguesa da Secretaria de Estado de Educação do Rio de Janeiro.

http://orcid.org/0000-0001-9199-225X | felipe.letras.ac@ gmail.com
} 


\title{
CORRESPONDÊNCIA DE MÁRIO: "UMA CIRANDA DE PAPEL"
}

Os estudos sobre correspondência têm aumentado nas últimas décadas, justificados pela investigação em torno de acervos (cartas, diários pessoais, etc.). Tais estudos, motivados pelo fato de que correspondências constituem, sobretudo, fontes primárias, são divulgados nos mais variados centros de pesquisa documental e arquivística espalhados pelo Brasil. Um deles é a "Organização da correspondência de Mário de Andrade”, disponível no Instituto de Estudos Brasileiros, IEB-USP.

O relato de Telê Ancona Lopez, a respeito da organização desse arquivo primário, traduz com nitidez todo o trabalho empreendido em torno da "ciranda de papel", como ela chama afetuosamente o acervo da correspondência de Mário:

\begin{abstract}
A correspondência, quanto à natureza, arrebanha cartas, ofícios, bilhetes, mensagens em postais e em telegramas. Constitui-se de autógrafos - lápis, lápis preto em geral, tintas de várias cores, letras de mil talhes -, datiloscritos originais ou cópia carbono e bem poucos textos mimeografados. Como suporte apresenta folhas de papel de todo tipo, cartões-postais, cartões de visita, de luto, e os primeiros cartões de Natal norte-americanos remetidos pelo casal Luiz Heitor Corrêa de Azevedo e pelo pintor Portinari, assim como os impressos da burocracia postal. (LOPEZ, 2000, p. 284)
\end{abstract}

De acordo com Lopez (2000, p. 277), Mário de Andrade, por mobilizar uma intensa atividade intelectual em torno de si, teve a oportunidade de corresponder-se com aproximadamente 1400 destinatários, com quem teve cartas trocadas por períodos bem duradouros (atentar para a correspondência trocada com Manuel Bandeira, por exemplo). Ainda de acordo com a autora, Mário de Andrade pode ser alcunhado de "polígrafo", já que a sua obra epistolar compara-se a outras obras universais, pelo fato de constituir um texto sempre revisitado por especialistas e interessados em correspondência.

Ainda de acordo com Lopez (2000, p. 280), Mário de Andrade correspondeu-se com Manuel Bandeira, Carlos Drummond de Andrade, Prudente de Moraes, Sérgio Buarque de Holanda, Paulo Prado, Sérgio Milliet, Murilo Mendes, Rosário Fusco, Fernando Sabino, Murilo Rubião, Henriqueta Lisboa, Câmara Cascudo, Moacir Werneck de Castro, Carlos Lacerda, Murilo Miranda, Anita Malfatti, Tarsila do Amaral, Brecheret, Portinari, Segall, Pettoruti, Villa-Lobos, Gallet, Lorenzo Fernandez, Mignone, Guarniere, Renato Almeida, Luiz Heitor Corrêa de Azevedo, Capanema, 
Rodrigo Melo Franco de Andrade, para citar as personalidades mais próximas ao modernista em algumas décadas de correspondência ativa e passiva.

É notório destacar que todo o trabalho do Instituto de Estudos Brasileiros, empreendido por Telê Ancona Lopez (2000, p. 275- 285) e por sua equipe, ressalta o aspecto primário da correspondência de Mário de Andrade, na medida em que um trabalho cuidadoso e que requer método rigoroso na separação dos documentos foi empregado, com o intuito único de divulgar a obra monumental do modernista que faleceu na década de 1940, mas ainda continua motivando pesquisas por sua solidez intelectual atemporal.

Além de revelar a produtividade intensa do autor, a correspondência organizada no IEB -USP oportuniza, no discurso de Lopez (2000, p. 282), o reconhecimento da riqueza intelectual das fontes primárias (como são chamadas, em termos técnicos, as correspondências em biblioteconomia), já que em meio a uma robusta poligrafia estão outros textos de inestimável valor intelectual, como poemas de Manuel Bandeira e de Carlos Drummond de Andrade, todos trocados em correspondências em que Mário tinha a oportunidade de intervir no texto alheio seja sugerindo um estilo do português brasileiro, seja convidando os outros intelectuais para a reflexão da brasilidade. Lopez acrescenta que:

\footnotetext{
Notas apostas a cartas e telegramas, algumas folhas amassadas, abandonado um primeiro desejo de jogar fora, nos asseguram que Mário de Andrade reconhecia perfeitamente o valor de sua correspondência. Vislumbrava a contribuição que esse diálogo daria, no futuro, ao trabalho dos que viessem a 'fazer a história' do modernismo, apoiados em fontes primárias. (LOPEZ, 2000, p. 280)
}

\section{MINHA ESCRITA, SUA ESCRITA}

Das três cartas analisadas neste trabalho, extraídas do livro A lição do amigo: cartas de Mário de Andrade a Carlos Drummond de Andrade (1982), a primeira delas porta em seu conteúdo temático duas vertentes da correspondência de Mário de Andrade, a saber: i) a autoavaliação que o autor faz da sua profissão; ii) a avaliação que o autor faz dos intelectuais de seu tempo. Para analisar essas duas vertentes, valemo-nos da correspondência do dia 10 de novembro de 1924. 
De imediato, esta carta do dia 10 de novembro de 1924 revela um Mário de Andrade preocupado e comprometido com a correspondência. Em meio à multiplicidade intelectual, Mário ressalta quase que a sua obrigação de não deixar o circuito emissão-recepção das cartas ser interrompido:

Eu respondo sempre aos amigos. Às vezes demoro um pouco, mas nunca por desleixo ou esquecimento. As solicitações da vida é que são muitas e as da minha agora muitíssimas e... Quer saber quais são? Tenho o meu trabalho cotidiano, é lógico. Lições no Conservatório, lições particulares. (ANDRADE, 1982, p. 3)

Todo o texto é organizado como autoavaliação de Mário como intelectual e na avaliação contundente que o autor empreende ao seu círculo de amizades, sobretudo, em relação a Carlos Drummond de Andrade. O texto transita, grosso modo, entre os pontos que soam ao leitor atento como conselhos de um escritor que está no auge do seu amadurecimento intelectual, mas também soam como forma constante de aprendizado do fazer intelectual a partir das experiências alheias.

A dose de conselho está, por exemplo, em trechos como "Tudo está em gostar da vida e saber vivê-la. Só há um jeito feliz de viver a vida: é ter espírito religioso" (ANDRADE, 1982, p. 3). Neste tópico, assim como em outros da correspondência do autor, o conselho corporifica, na verdade, a intensa participação de Mário de Andrade como uma figura pública de início do século XX. A escolha pela intelectualidade e pela defesa de uma cultura brasileira passa pela justificativa de que as tantas frentes de atuação de Mário são fontes de prazer estético constantemente revisitado em sua correspondência.

$\mathrm{Na}$ esteira do registro epistolar enviesado pelo aconselhamento, Mário continua: "Eu acho, Drummond, pensando bem, que o que falta pra certos moços de tendência modernista brasileiros é isso: gostarem de verdade da vida (ANDRADE, 1982, p. 4)". Neste tópico da carta de novembro de 1924, Mário tece uma dura crítica ao intelectual de gabinete, que, para ele, seria um intelectual cujas experiências são ceifadas pela burocracia, geralmente atribuída ao funcionalismo público, e cuja aproximação ao cerne da arte pautada na vivência perde-se no ir e vir da arte que se mistura aos papéis das repartições públicas: 
Eu não posso compreender um homem de gabinete e vocês todos, do Rio, de Minas, do Norte me parecem um pouco de gabinete demais. Meu Deus! Se eu estivesse nessas terras admiráveis em que vocês vivem, com que gosto, com que religião eu caminharia sempre pelo mesmo caminho (...). (ANDRADE, 1982, p. 4)

A avaliação do "outro" ("parecem um pouco de gabinete demais") e o próprio ensejo do conselho ("eu caminharia sempre pelo mesmo caminho") revelam que Mário de Andrade ataca a erudição pela erudição, na medida em que toda esta carta direciona a desconstrução das expectativas que devem recair sobre o intelectual: devolver à sociedade uma arte engajada, comprometida e, ao mesmo tempo, também poder oferecer a arte erudita. Mário o faz, mas há ressalvas: o comprometimento com a arte não é abandonado por ele, o que parece emergir de sua correspondência é paulatinamente a construção de um intelectual que resgata o saber primitivo, ou seja, a expressão artística de seu país refaz-se na cultura popular, sem ser popularesca.

No auge de sua maturidade artística, Mário de Andrade aponta-nos o caminho inverso: "E então parar e puxar conversa com gente chamada baixa e ignorante! Como é gostoso! Fique sabendo duma coisa, se não sabe ainda: é com essa gente que se aprende a sentir e não com a inteligência e a erudição livresca" (ANDRADE, 1982, p. 4-5). Neste item da carta de novembro de 1924, o intelectual encarna o etnógrafo para quem toda a experiência com a arte primitiva é motivo para o fazer da própria arte. Portanto, ao mesmo tempo em que questiona a arte de Drummond e de outros intelectuais, Mário revela a orientação de sua arte e sugere-nos a seguinte chave de leitura: o intelectual deve experienciar a arte primitiva e popular de sua nação.

A carta de novembro de 1924 é permeada de exemplos nos quais Mário sugere este retorno à outra esfera do saber/fazer artístico, a esfera popular. Um desses exemplos torna-se significativo, na medida em que o intelectual despe-se de sua postura reclusa, como a criticada no intelectual de gabinete, e sai a campo para coletar dados fundamentais à sua arte: trata-se de uma experiência de Mário com o carnaval de rua do Rio de Janeiro, em que tem a oportunidade de ver/experienciar a dança de negros que cruzam a Avenida Rio Branco na efervescência do samba e da passagem a céu aberto. Mário convida-nos, nesta experiência, a focar, tanto no texto da carta quanto na própria cena descrita do desfile, a origem ou o mote de sua arte.

O registro da correspondência de novembro de 1924 convida-nos a desvelar, ou antes violar, a avaliação que Mário empreende nos textos enviados por Drummond: 
"Segundo: li seu artigo. Está muito bom. Mas nele ressalta bem o que falta a você espírito de mocidade brasileira. Está bom demais pra você” (ANDRADE, 1982, p. 6). Aqui, há claramente uma tentativa de questionar, na escrita de Drummond, as remissões que o poeta itabirano (aspirante a escritor) opera em sua escrita pautada nas leituras francesas da juventude. $\mathrm{O}$ registro desta carta encaminha nitidamente a noção de que ambos se enviavam textos produzidos no cenário intelectual do início do século XX e encaminha, ainda, a noção de que ambos haviam firmado um contrato no qual o melindre da avaliação no texto/arte do outro sofreu um processo de maturação.

Tanto a busca pela arte primitiva do Brasil quanto a falta de um olhar perspicaz no jovem poeta itabirano são razões para que Mário faça um convite ao próprio Drummond e às outras gerações de artistas brasileiros de seu tempo. É aqui que Mário faz o convite: "Carlos, devote-se ao Brasil, junto comigo (...) nós temos que dar uma alma ao Brasil” (ANDRADE, 1982, p. 5). Mais uma vez a intervenção de Mário encaminha-se no sentido de que, por muito tempo, o Brasil viveu a arte do mimetismo, e, só agora, com as gerações de artistas modernistas, pode-se vislumbrar o ineditismo nas artes brasileiras. Neste sentido, a avaliação de Mário sobre o fazer artístico de Drummond incide no fato de que os modelos franceses devem ser superados como potencialidades para vivenciar e contemplar as demandas artísticas do Brasil.

Entre a avaliação da arte de Drummond e a sua própria arte, Mário de Andrade pretende ser a voz da maturidade intelectual, mas traz um tom de consciência de sua contribuição para as letras brasileiras, ainda que saibamos que seja modesto:

Toda a minha obra é transitória e caduca, eu sei. E eu quero que ela seja transitória. Com a inteligência não pequena que Deus me deu e com os meus estudos, tenho a certeza de que eu poderia fazer uma obra mais ou menos duradoura. Mas que me importa a eternidade entre os homens da Terra e a celebridade? (ANDRADE, 1982, p. 6)

O que se pode observar no binômio duradouro-efêmero é mais uma vez a oportunidade que tem o artista de mesclar intelectualidade e argúcia investigativa, na medida em que, como sugere o missivista, a arte não pode ficar aprisionada apenas nos condicionamentos intelectuais do seu produtor, ela deve ser também a oportunidade para a socialização do conhecimento captado e retribuído de uma geração. Em linhas gerais, o convite de Mário feito a Drummond é claramente a busca por parcerias 
intelectuais para a construção de uma identidade nacional pautada em modelos (re)inventivos e conscientes da arte.

É já no fim da carta de novembro de 1924 que vem o apanhado da lição de Mário em torno dos conselhos e da acusação pontual: "O importante não é ficar, é viver. Eu vivo. E vocês não vivem porque são uns despaisados e não têm a coragem suficiente pra serem vocês" (ANDRADE, 1982, p. 6). Percebe-se aqui que Mário, além de mostrar vigor intelectual motivante, dá ou, mais uma vez, sugere a saída para os jovens intelectuais brasileiros em processo de maturação estética.

A carta de novembro de 1924 oportuniza, ainda, a noção de que Mário dedicavase incansavelmente à escrita da correspondência. No fim dessa carta, ele reconhece: "Eu sofro de gigantismo epistolar" (ANDRADE, 1982, p. 6). Trata-se, em linhas gerais, de um registro que nos permite violar o cerne crítico da escrita de Mário, em que não só há críticas contundentes a respeito da arte de Drummond, mas também um olhar rigoroso sobre o próprio fazer de intelectual múltiplo.

\section{UM CONVITE AO PRIMITIVISMO}

Na correspondência de Mário endereçada a Drummond, somos incitados a revisitar um tema oportuno do modernismo brasileiro: o uso da linguagem na literatura de início do século XX. Vale lembrar que a crítica que os modernistas (sobretudo Oswald de Andrade, Mário de Andrade e Manuel Bandeira) encaminham é sobre nossa submissão de linguagem a um modelo lusitano de conceber literatura e é sobre, ainda, nossa retórica esvaziada de identidade nacional/primitiva.

A carta que passamos a analisar não tem data, mas torna-se bastante significativa em relação ao tema do "abrasileiramento" sugerido por Mário de Andrade a Carlos Drummond de Andrade. A síntese da sugestão de Mário para um estilo essencialmente brasileiro consta neste seguinte excerto:

É preciso começar esse trabalho de abrasileiramento do Brasil, dizia eu noutra carta, a um rapaz de Pernambuco. E agora reflita bem no que eu cantei no final do "Noturno" e você compreenderá a grandeza desse nacionalismo universalista que eu prego. (ANDRADE, 1982, p. 15) 
O combate de Mário aos modelos literários importados, sobretudo de Portugal, é uma das tônicas do movimento modernista que abre espaço para e reflexão de uma arte que deve ser menos imitação e mais originalidade. Na correspondência de Mário a Drummond, a pontualidade das intervenções estilísticas faz com que a poesia deste seja uma mostra de como aquele pretende ser o porta-voz do abrasileiramento, seja na sugestão de uma regência verbal brasileira, seja na sugestão de supressões necessárias no que tange à mera cópia de modelos europeus.

A análise dessa carta, que no livro organizado por Drummond ganha posição de segunda carta, é significativa uma vez que nela Mário evidencia acentuadamente o trânsito das correspondências entre ele e Drummond (basta observar o que ele diz no segmento "Gosto muito de receber cartas" (ANDRADE, 1982, p. 12). Nesta correspondência, o autor de Paulicéia desvairada deixa evidente que muitos eram os assuntos das correspondências, mas um deles chama a atenção: a troca de textos diversos (artigos, poemas, contos, peças, etc.) entre ele e o poeta itabirano.

Nesta correspondência, Mário tece uma crítica contundente e até mesmo áspera em relação a um artigo que Drummond endereçou-lhe. Trata-se de um artigo em que Drummond fala da herança intelectual advinda de Anatole France. O combate de Mário ao que Drummond escreve sobre Anatole ganha destaque aqui: "O mal que esse homem fez a você foi torná-lo cheio de literatices, cheio de inteligentices, abstrações em letra de forma” (ANDRADE, 1982, p. 13). A crítica de Mário à influência que os literatos franceses exerciam nos poetas e romancistas brasileiros parece ser o cerne desta correspondência, em que a sugestão da originalidade (ou do abrasileiramento) endossa a maturidade de Mário frente a outros artistas brasileiros.

Em outra carta do dia 01 de agosto de 1926, Mário fala o quão importantes são intervenções de Manuel Bandeira em seu estilo e sugere que o "abrasileiramento" é, de fato, um fator de influência dos modernistas que alcançaram a maturidade intelectual sobre os outros que ainda caminhavam nesta direção: "Aí vão as notas que tomei numa última leitura do livro seu. Fiz isso irmãmente quem nem o Manu faz comigo e eu com ele. Acho que você sabe apreciar essa sem-cerimônia" (ANDRADE, 1982, p. 80). Esta segunda carta do livro A lição do amigo (1982) é permeada de intervenções de Mário no estilo de Drummond. 
O poeta paulista endossa ainda mais essa intervenção necessária dos artistas brasileiros:

O que nós todos queremos (o que pelo menos imagino que todos queiram) é obrigar este velho e imoralíssimo Brasil dos nossos dias a incorporar-se ao movimento universal das ideias. Ou, como diz Manuel Bandeira, 'enquadrar, situar a vida nacional no ambiente universal, procurando o equilíbrio entre os dois elementos'. Vaidadinha. Se lembra da Paulicéia? (ANDRADE, 1982, p. 14)

E continua: "O despaisamento provocado pela educação em livros estrangeiros" (ANDRADE, 1982, p. 15) seria, segundo ele, o que tira a identidade nacional da arte produzida no Brasil e, pior ainda, pinta um Brasil menos brasileiro e mais regionalista, na acepção mais depreciativa do termo. Uma palavra-síntese é usada por Mário para referir-se a essa cópia desenfreada dos modelos europeus, isto é, "macaqueação", não no sentido de ser uma arte mimética, mas uma arte que imita por imitar.

Os neologismos de Mário proliferam-se nesta carta. O termo "desprimitivar" (ANDRADE, 1982, p. 15) é usado por ele para referir-se ao fato de que ainda não aprendemos a ser uma civilização. A metáfora que enseja a noção de "desprimitivar": "Quando realizarmos o nosso acorde, então seremos usados na harmonia da civilização" (ANDRADE, 1982, p. 15) é mais uma prova de que Mário quer fazer do Brasil uma potência intelectual com originalidade como qualquer outra do mundo, sobretudo a dos franceses e dos alemães.

Mário compara, nesta carta, a prosa e a poesia de Drummond e chega à conclusão de que o poeta itabirano se destaca melhor na composição em prosa, justamente porque ainda concebe a arte da prosa de acordo com os ideais franceses, até então criticados. Neste sentido, toda a análise de Mário sobre o artigo de Drummond revisita o par opositivo nacional versus universal, uma vez que o que parece estar claro para Mário ainda é um "empecilho" na arte de Drummond, o que se evidencia no prefácio de Paulicéia desvairada: "ninguém se liberta duma vez das teorias avós que bebeu", conforme sugere Mário (1982, p. 17).

Depois de tecer crítica contundente à falta de maturidade intelectual em Drummond, Mário, como costuma fazer em sua correspondência, anexa ao fim de suas sugestões e demandas intelectuais os poemas de Drummond acrescidos de intervenções de ordem estilística, com a seguinte justificativa: 
Como pratico com o Manuel Bandeira e o Luís Aranha, e eles comigo, mando-te os teus versos com algumas sugestões. Mas quero que eles voltem pra mim. Preciso deles em minha casa enquanto não se publicam. (ANDRADE, 1982, p. 17)

Nesta medida, antes de os textos de Drummond serem encaminhados ao prelo, tinham alguns deles a revisão e a leitura criteriosas de Mário. Passemos a uma breve análise de algumas das intervenções gramaticais e estilísticas operadas, neste caso, em quatro poemas de Drummond.

No poema "Política", Mário sugere, por exemplo, que Drummond escreva com menos pronomes possessivos os versos "Ele vivia isolado na sua casa; / seus amigos abandonaram-no", e sugere que os versos sejam escritos com certa precaução no uso desses pronomes: "isolado em casa / amigos abandonaram-no" (ANDRADE, 1982, p. 18). Nesta mesma proposta de escrita autoral, Mário ressalta: “Que abundância francesa de possessivos!" (op. cit.) de modo a ratificar a influência francesa nos textos do itabirano.

A mesma influência francófona pode ser notada em outro poema revisado por Mário, "Construção". Aqui, o poeta itabirano emprega excessivamente em seu poema o artigo indefinido "um" como se pode observar em: "Um grito pula no ar como um foguete", ao que Mário imediatamente sugere: "O grito" e "como foguete" (ANDRADE, 1982, p. 18-19) de modo a apontar mais uma vez certa influência do francês nos versos ("Que abundância francesa de uns!”), o que sugere a orientação das vanguardas europeias entre os modernistas.

No âmbito da regência verbal, tópico que os linguistas colocam em xeque nas variedades muito antagônicas da língua, parece que Drummond já tinha alcançado certa maturidade de abrasileiramento. No poema "Nota social", também enviado a Mário, o primeiro verso "O poeta chega na estação" ganha o seguinte comentário de Mário: " $n a$ estação gostei da regência. Bravo!” (ANDRADE, 1982, p. 19). Bem se vê que a convivência com outros modernistas, sobretudo em troca de correspondência constante com Mário, faz com que Drummond adote uma poética muito mais condizente com um suposto português brasileiro que começa a se delinear nas primeiras décadas do século XX. 
Já no âmbito da seleção vocabular, observa-se que, além de tecer uma crítica contundente e paulatina sobre a influência francesa na poética de Drummond, Mário ainda revisita, de modo bastante seguro, a cópia desenfreada dos modelos lusitanos. No poema "Passa uma aleijadinha", à certa altura encontra-se o verso "acha uma muleta aqui, outra acolá", que imediatamente é rechaçado por Mário: "acolá Que palavra horrível! Só se emprega em livros didáticos. Deixemos isso pra Portugal" (ANDRADE, 1982, p. 20).

Como se vê, a criteriosa intervenção de Mário nos textos de Drummond encaminha a crítica em relação à necessidade de tornar a arte dita brasileira cada vez mais liberta dos modelos europeus. As palavras de Pinto ${ }^{1}$ endossam o abrasileiramento sugerido pelo autor de $O$ turista aprendiz:

Mário de Andrade procurou detectar as "tendências e constâncias" do uso nacional da língua portuguesa e recolher os traços mais pertinentes, para fins de caracterizar a expressão literária brasileira. De forma semelhante procedeu Guimarães Rosa (...). (PINTO, 2008, p. 523)

\section{ARTISTA PARA MÁRIO DE ANDRADE: ETNÓGRAFO}

As cartas analisadas neste trabalho sugerem um Mário de Andrade etnógrafo, ou seja, um artista que "sai do seu gabinete" à procura do relato popular, para fazer deste relato a matéria-prima para a sua arte. Nas palavras de Telê Ancona Lopez:

\footnotetext{
A viagem à Amazônia, a julgar-se pelos textos de 1927 e 1928 que dela resultaram, foi claramente marcada pela preocupação etnográfica, com Mário de Andrade procurando entender uma particularidade do Brasil através da observação da vida do povo. Ela teria também lhe mostrado a necessidade de pôr logo em prática seu velho projeto de visita ao nordeste, desejando agora realizar uma pesquisa mais sistemática em uma região que se oferecia tão rica em tradição musical popular. (LOPEZ, 1976, p. 19)
}

Em carta datada de 12 de março de 1932, Mário de Andrade diz a Drummond que a sua viagem a Minas Gerais só não durou muito porque estava com febre. Bem se vê que, além de trocar cartas com Drummond, Mário ainda tem a preocupação de visitar o centro histórico de Ouro Preto, na tentativa de fotografar os monumentos (igrejas e fachadas históricas) para a produção de artigos em revistas. 
É interessante notar que, em várias passagens da carta, Mário fala sobre o seu estado febril como um empecilho para a viagem de coleta de dados pelo centro histórico:

\begin{abstract}
Carlos,
Crocotó! Lá se foi minha viagem pra Minas mais uma vez! Fiquei desesperado foi do meu espevitamento de pôr as coisas como queria que estivessem postas, sem me lembrar que Deus é que dispõe. Explico o fato: Eu andei muito doente, mas pouco a pouco fui melhorando, todos os sintomas da doença se acabaram, estava certo de que estava curado. (1982, p. 173)
\end{abstract}

Nesta carta, Mário de Andrade já se mostra sobrecarregado em relação à quantidade de viagens empreendidas pelo Brasil. Vale ressaltar que esta carta datada de 1932 foi escrita após a elaboração do romance Macunaíma, cujo trabalho etnográfico (de pesquisa de campo pelo Norte e pelo Nordeste do país) tinha sido intenso.

Segundo Lopez (1976, p. 19), todo o trabalho de coleta feito por Mário em viagens pelo Brasil constava em seu diário: "ao longo da viagem irá registrando suas impressões num diário, com a intenção de transformá-lo num futuro livro de viagens, a que chamaria de O turista aprendiz, conforme declara em entrevista dada em São Paulo, quando de seu regresso". Como se vê, a pretensão de Mário era reunir um vasto material sobre os costumes de toda ordem (música, dança, vestimentas, religiosidades) tanto para a produção de seu romance Macunaíma quanto para a escrita de crônicas reunidas postumamente em livro, como aponta Lopez (1976, p. 21).

O etnógrafo continua:

Depois tenho as experiências e novos exames de laboratório, não posso partir. Tanto mais que Minas, sem pelo menos seis dias, não me convém. Era impossível gastar o dinheirão da viagem sem pelo menos refazer Ouro Preto, Congonhas, Mariana, e Belo Horizonte (ANDRADE, 1982, p. 173).

De modo geral, nota-se que as viagens empreendidas por Mário se tornam também o motivo para a escrita epistolar, na medida em que as viagens têm um caráter produtivo para o intelectual/artista fora do seu gabinete. Vale ressaltar que os blocos de anotação de Mário (alguns deles constituem acervo do Instituto de Estudos Brasileiros da USP) são instrumental poderoso para despertar a curiosidade artística para o desconhecido. 


\title{
CONSIDERAÇÕES FINAIS
}

A leitura do texto epistolar de Mário de Andrade endereçado a Carlos Drummond de Andrade deixa-nos a seguinte lição mencionada por Silviano Santiago:

\begin{abstract}
No universo da literatura, a carta existe para que o discípulo se dirija ao mestre. O discípulo precisa ser reconhecido enquanto tal. (Assim como nós, leitores, queremos ser reconhecidos como dignos da interlocução com mestres Carlos e Mário. Somos voyeurs e também aprendizes na leitura que faremos desta correspondência.) (SANTIAGO, 2002, p. 12)
\end{abstract}

Nesta travessia do texto epistolar de Mário de Andrade, o leitor tem muito a ganhar no sentido de que é incitado a todo momento à ânsia de descobrir uma confissão, de saber qual é o empreendimento cultural em que Mário e Drummond lançam-se, de ter os bastidores da amizade dos dois modernistas revelados. Nesta travessia-leiturareleitura, é o leitor também destinatário, na medida em que se trata de um texto epistolar para vários destinatários que precisam se auto convidar e enveredar na leitura.

Nesta travessia, ficam outras lições, a saber:

a) a correspondência de Mário de Andrade endereçada a Drummond convida-nos ao entendimento de que Mário participou ativamente da formação intelectual/artística de outros modernistas. Seja intervindo no texto, seja reorientando o estilo de outros modernistas, o texto epistolar de Mário é um legado para a história do modernismo brasileiro;

b) a correspondência de Mário de Andrade, antes de ser uma textualidade que se julga pronta, é a manifestação artística de um artista que vê na arte a oportunidade de voltar às raízes no processo de formação de uma identidade cultural brasileira. Portanto, é uma textualidade que convida o outro (neste caso Drummond e, por que não?, o leitor também) a refletir sobre o primitivismo da(s) linguagen(s);

c) a correspondência de Mário de Andrade é, portanto, um texto que revisita a práxis do artista, no sentido de que a todo momento o incita a ser um etnógrafo, ou seja, alguém que deseja conhecer mais da cultura do outro. Alguém que precisa sair a campo para, com muita curiosidade e perspicácia, coletar dados para fazer-se intelectual/artista.

Vale destacar que a leitura de cartas não tem a pretensão de encerrar uma única interpretação sobre o texto. A leitura de cartas torna-se releitura, ou, em um termo mais 
correto, revisitação, já que o texto epistolar apresenta pistas de leitura que, a depender da porta de entrada, assumirá feições diferenciadas pelo fato de que cada leitor terá uma chave para adentrar a densidade do texto e pelo fato de que cada leitor é um contribuinte nas várias leituras. Neste trabalho, a leitura adotada de Mário de Andrade pretende ser uma contribuição em meio às poucas leituras feitas em correspondência.

\section{Referências}

ANDRADE, Mário de. A lição do amigo: cartas de Mário de Andrade a Carlos Drummond de Andrade. Rio de Janeiro: José Olympio, 1982.

LOPEZ, Telê Ancona. "Uma ciranda de papel: Mário de Andrade destinatário". In: GALVÃO, Walnice Nogueira et al (org.). Prezado senhor, prezada senhora: estudos sobre cartas. São Paulo: Companhia das Letras, 2000. p. 275-285.

LOPEZ, Telê Ancona. "Prefácio". ANDRADE, Mário de. O turista aprendiz. São Paulo: Duas cidades, Secretaria da Cultura, Ciência e Tecnologia, 1976. p. 1-21.

PINTO, Edith Pimentel. "Século XX". In: SPINA, Segismundo (org). História da lingua portuguesa. Cotia, São Paulo: Ateliê Editorial, 2008. p. 517-581.

SANTIAGO, Silviano. "Suas cartas, nossas cartas". In: ANDRADE, Carlos Drummond de. Carlos e Mário: correspondência entre Carlos Drummond de Andrade - inédita -e Mário de Andrade. Rio de Janeiro: Bem-Te-Vi, 2002. p. 7-33.

Recebido em: 31/01/2020

Aceito em: 18/07/2020

\footnotetext{
${ }^{1}$ Na obra A gramatiquinha de Mário de Andrade (1990), organizada por Edith Pimentel Pinto, expõem-se todos os bastidores acerca da defesa de Mário sobre uma língua essencialmente brasileira.
} 